\title{
WORLDVIEW
}

ONE YEAR

\section{[10 ISSUEST}

$\$ 250$

Name

Address

City

State

Zlp

\section{BIGGER SAVINGS}

口 I prefer to seve $\$ 7$. Enter my subscription for two years ( 20 issues) for only $\$ 18$. 


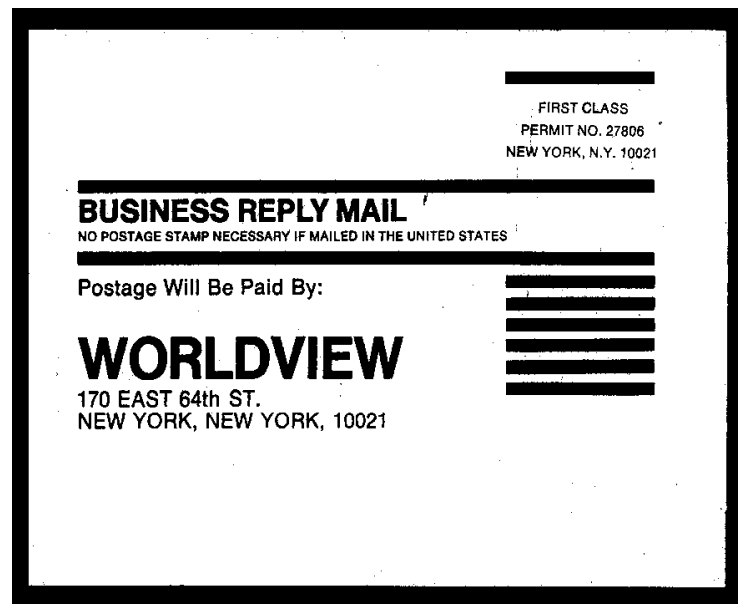




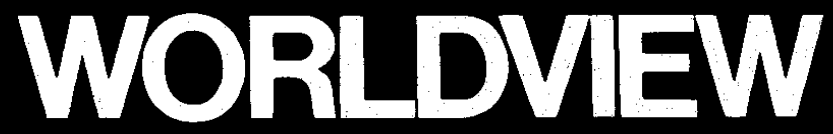

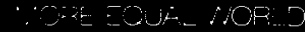

$\because$ PIV APHOF THE HORSE
INTERVIEW WITH IRVING LOUIS HOROWITZ

ANDRE VAN DAM

HE TERROR OF JEAN-PAUL SARTRE

SAMAUEL HUX

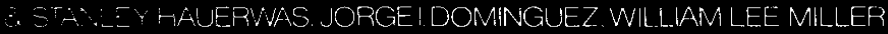 ZWHAD JOHN NEUHAUS. JAMES FHN}

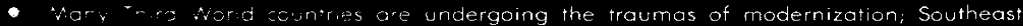
As 5 sa of the iosa bonts at which industrial power runs head on into traditional life $\therefore$ ars Raph Bublieris a natwe of Sri tanka and a political scientist, examines that -..nt a ard ponts at pt ons for the future. Some are better than others, but not at this andane more likely

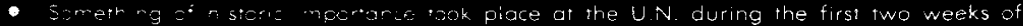

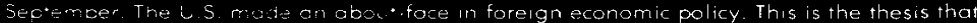

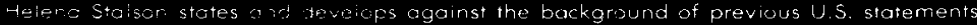
and bo: zes. A 'ively, provocative, and chollenging statement.

- Gett j down ar the skins." A tronslation of balar cueros, the common expression the stioestifie boys of Latin America apply to their jobs. Jeffrey $C$. Jacob describes what he boser ed $n$ a long period of close examination of the young shoeshine boys of $3 a^{+}$-ndalo tis conclusions about the consequences of early and uncertain employment :- on and suprising. In the January-Februgry issue

\section{Published by the Council on Religion and International Affairs}




\section{RESOLUTION CHART}

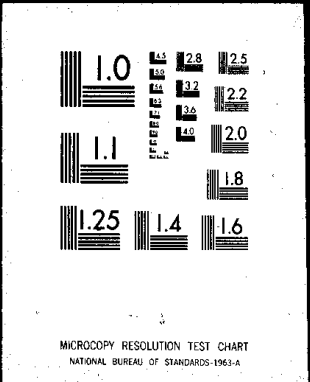

100 MILLIETES

INSTRUCTIONS Resolution is expressed in terms of the lines per millimeter recorded by a particular film under specified conditions. Numerals in chart indicate the number of lines per millimeter in adjacent "T-shaped" groupings.

In microfilming, it is necessary to determine the reduction ratio and multiply the number of lines in the chart by this value to find the number of lines recorded by the film. As an aid in determining the reduction ratio, the line above is 100 millimeters in length. Measuring this line in the film image and dividing the length into 100 gives the reduction ratio. Example: the line is $20 \mathrm{~mm}$. long in the film image, and $100 / 20=5$.

Examine "T-shaped" line groupings in the film with microscope, and note the number adjacent to finest lines recorded sharply and distinctly. Multiply this number by the reduction factor to obtain resolving power in lines per millimeter. Example: 7.9 group of lines is clearly recorded while tines in the 10.0 group are not distinctly separated. Reduction ratio is 5 , and $7.9 \times 5=39.5$ lines per millimeter recorded satisfactorily. $10.0 \times 5=50$ lines per millimeter which are not recorded satisfactorily. Under the particular conditions, maximum resolution is between 39.5 and $50^{\circ}$ lines per millimeter.

Resalution, as measured on the film, is a test of the entire photographic system, including lens, exposure, processing, and other factors. These rarely utilize maximum resolution of the film. Vibrations during exposure, lack of critical focus, and exposures yielding very dense negatives aré to be avoided.

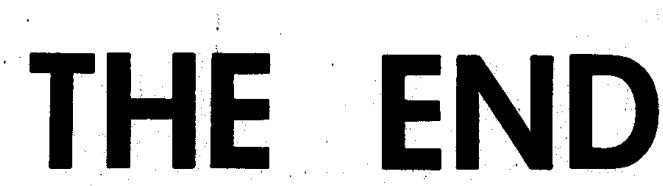

